\title{
ОПРЕДЕЛЕНИЕ КОНЕЧНЫХ ПРОДУКТОВ СИНТЕЗА СТЕРОИДОВ - 18-ГИДРОКСИКОРТИЗОЛА, 18-ОКСОКОРТИЗОЛА МЕТОДОМ ВЭЖХ-МС/МС В ДИФФЕРЕНЦИАЛЬНОЙ ДИАГНОСТИКЕ РАЗЛИЧНЫХ ФОРМ ПЕРВИЧНОГО ГИПЕРАЛЬДОСТЕРОНИЗМА
}

\author{
Романова Н.Ю., Иоутси В.А., Богданов В.П., Платонова Н.М., Трошина Е.А. \\ ФГБУ «НМИЦ эндокринологии» Минздрава России, Москва
}

\begin{abstract}
АКТУАЛЬНОСть: Альдостеронсинтаза участвует в ключевых реакциях синтеза альдостерона 11-гидроксилирование, 18-гидроксилирование и, наконец, 18-окисление. В работах последних лет, посвященных оценке эффективности применения гибридных стероидов в дифференциальной диагностике подтипов ПГА, стоит подчеркнуть опыт применения высокоэффективной жидкостной хроматографии тандемной масс-спектрометрии (ВЭЖХ-МС/MC), позволяющей выявлять даже очень низкую их концентрацию в периферической плазме (нижняя граница для 18-оксокортизола - 0.25 нг/дл). Соответственно, измерение в периферической крови концентрации 18-гидроксикортизола, 18-оксокортизола с использованием BЭЖХ-MC/MC для дифференциальной диагностики форм ПГА является актуальной.
\end{abstract}

ЦЕЛЬ: оценить различия в синтезе конечных продуктов стероидов методом ВЭЖX-MC/MC при различных формах первичного гиперальдостеронизма

МАТЕРИАЛЫ И МЕТОДЫ: ретроспективная оценка образцов сыворотки крови 136 пациентов с верифицированным диагнозом первичный гиперальдостеронизм, направленных на стационарное лечение в отдел терапевтической эндокринологии ФГБУ «НМИЦ эндокринологии» Минздрава РФ. В соответствии со стандартными протоколами проводилась оценка показателей стероидогенеза - альдостерона, 18-оксокортизола, 18-гидроксикортизола, 18-гидроксикортикостерона, 20b-дигидрокортизона, кортизона, кортизола, тестостерона, 21-дезоксикортизола, кортикостерона, 11-дезоксикортизола, андростендиона, 11-дезоксикортикостерона, ДГЭА, 17-ОН прогестерона, 17-ОН прегненолона, прогестерона, прегненолона, андростендиона, адреностерона, 11-гидроксиандростендиона методом ВЭЖХ-МС/MC.

PЕЗУЛЬтАТЫ: в рамках проведенного исследования у 136 пациентов: с АПА $(n=56)$, ИГА ( $n=24)$ и 56 с ГНО проведено исследование стероидогенеза, включая определение конечных продуктов синтеза стероидов - 18-гидроксикортизола, 18-оксокортизола методом ВЭЖХ-МС/МС. Установлено, что у пациентов с альдостеромой уровень 18-оксокортизола, гидроксикортизола, 18-гидроксикортикостерона, прегненолона, определяемых методом ВЭЖХ-МС/MC, статистически значимо повышены по сравнению с исследованием таковых у пациентов с гормонально-неактивными образованиями надпочечника в сочетании с АГ (18-Oxocortisol $\mathrm{Me}_{\text {(пга) }} 0,75[0,13 ; 1,98]$ нг/дл, $\mathrm{Me}_{(\text {гно) }} 0,1[0,06 ; 0,14]$ нг/дл, $\mathrm{p}<0,05$; 18-Hydroxycortisol $\mathrm{Me}_{\text {(пга) }} 5$ [2,52; 10,95] нг/дл, $\mathrm{Me}_{(\text {гно) }} 2,4[2 ; 3,44] \mathrm{нг} / д л, \mathrm{p}<0,05 ; 18$-Hydroxycorticosterone $\mathrm{Me}_{\text {(ПгА) }} 3,48[1,97 ; 7,02] \mathrm{нг/дл,} \mathrm{Me}_{\text {(гно) }} 1,76[1,25 ; 2,52]$ нг/дл, $\mathrm{p}<0,05 ;$ Pregnenolone $\mathrm{Me}_{\text {(пгА) }} 2,22[1,4 ; 3,07]$ нг/дл, $\mathrm{Me}_{(г \text { но) }} 1,38[0,98 ; 2,19]$ нг/дл, $\left.\mathrm{p}<0,05\right)$. При этом, в группе пациентов с ПГА ( $\left.\mathrm{n}=80\right)$ уровни 18-оксокортизола и 18-гидроксикортизола статистически значимо повышены у пациентов с АПА по сравнению с исследованием у пациентов с ИГА (18-Oxocortisol Me (АпА) $1,04[0,33 ; 2,68]$ нг/дл, $\mathrm{Me}_{\text {(игА) }} 0,14[0,08 ; 0,67]$ нг/дл, p<0,05; 18-Hydroxycortisol $\mathrm{Me}_{\text {(АпА) }} 6,7[4 ; 15,35]$ нг/дл, $\mathrm{Me}_{\text {(ИгА) }} 2,68[1,96 ; 4,44]$ нг/дл, $\left.\mathrm{p}<0,05\right)$.

Выводы: таким образом, доказана целесообразность определения 18-оксокортизола и 18-гидроксикортизола методом ВЭЖХ-МС/МС в дифференциальной диагностике различных форм первичного гиперальдостеронизма. 